\title{
Not Known if NRAS Mutation Analysis Was Performed
}

National Cancer Institute

\section{Source}

National Cancer Institute. Not Known if NRAS Mutation Analysis Was Performed. NCI

Thesaurus. Code C160462.

An indication that it is not known whether NRAS rearrangement analysis was performed during the study. 